Original Article

\title{
Gender disparities in academic rank and writing amongst medical faculty members
}

Ayesha Fahim ${ }^{1}$, Fahim Haider Jafari ${ }^{2}$

1. Associate Professor Oral Biology, Azra Naheed Dental College, Superior University Lahore.

2. Professor of Anatomy, Majmaah University,

\section{ABSTRACT}

Introduction: Pakistan is a developing country with rich cultural values. With increased urban development and high workforce demands in the labor market during the last two decades, we have seen a positive shift in the stereotypical paradigm with an immense influx of female students in all fields of education including medicine. Although there is increased representation of female doctors, their academic contribution and representation in higher academic rank seem scarce.

Objective: In this study, we investigate gender differences in academic ranks and research in renowned Medical Institutions of Pakistan.

Methods: Websites of three institutions were used to identify male and female faculty members, their respective publications were counted using "Pakmedinet.com" and "Scholar.google.com".

Results: A one-way ANOVA showed a significant difference in the male-female ratio at higher academic ranks. This ratio drastically increases at the Full Professor level where males are three times more than female Professors. ANOVA results also show that publications by male faculty members are significantly higher than females. Even on the same rank, women have not published their work in the same capacity as men.

Conclusion: The results are in alignment with several previous studies that indicate gender disparities between males and females especially as they climb up the academic ladder. Publications are a measure of academic productivity. This study suggests that although female representation as faculty members have increased over the years, their lack of frequent publications might be a factor that hinders women in advancing in academic ranks.

KEYWORDS: Gender imbalance, academic productivity, medical institutions, Pakistan.

doi: https://doi.org/10.53708/hpej.v3i2.98

This is an Open Access article and is licensed under a creative commons attribution (4.0 International License)

\section{INTRODUCTION}

Pakistan is a developing country with its proud cultural values. Since the beginning, the patriarchal mindset dictates that the true worth of a female is her ability to be a good subordinate, raise kids and keep a good household (Halim, 1999; Rehman \& Roomi, 2012). Making round chapatis has been a symbol of a perfect woman in South East Asia (Zubair, 2016)). The reason behind this dilemma is the social values and traditional roots constructed by our predecessors (Ali et al., 2011). The right to education, freedom of speech, and work privileges have been major issues for early women in our society (Nussbaum, 1999; Coomaraswamy, 2017).

But with increased urban development and high workforce demands in the labor market during the last two decades, we have seen a positive shift in the stereotypical paradigm with an immense influx of female students in all fields of education including medicine (Van Der Velden et al., 2008). In Pakistan, the total number of registered female doctors was 11074 in 2005, the number increased to 93071 till September 2019, which is almost equivalent to 94899 male registered doctors (PM\&DC, 2019), the cream of our nation.

Correspondence:

Dr. Ayesha Fahim

Email address: ayeshafahim.af@gmail.com,

Received: Nov 13, 2019 Accepted: March 24, 2020

Funding Source: Nil
Like in other professions, doctors make a significant impact in the medical world through post-graduation and publications (Dhalla \& Detsky, 2011). Higher education and the greater number of published articles increase the academic productivity of faculty members that ultimately leads to promotions in the workplace (Dhulkhed et al., 2016). With this volume of female doctors graduating, we expect the same male-female ratio in higher medical ranks and research. In a recent article in "The News", it was pointed out that about 85000 qualified Pakistani female doctors are not currently employed (Bhatti, 2019). The writer suggests that being the primary caregiver of the household and lack of permission from In-laws might contribute to this number. This raises a few serious questions, what is the academic productivity of female doctors? Is our nation still infected with gender disparity?

To establish this, we reviewed the number of male and female faculty members in renowned medical institutes of Pakistan. We also examined the publication records of all these faculty members and compared male and female ratios. This study had two main objectives; to identify gender gaps in higher medical ranks, and to determine the difference in publications of male and female faculty members. Although this issue has been raised several times in the media, no scientific research is available that could pinpoint the current situation in Pakistan. 


\section{METHODS}

This study was conducted in the Department of Oral Biology, Azra Naheed Dental College, Superior University Lahore. The study was conducted via a descriptive quantitative design. After getting institutional review board approval, waiving the participant's consent, the websites of three highly-ranked Medical Institutes of Pakistan were reviewed These institutes were selected based on their quality assurance, the number of publications each year, social integration, teaching quality, and community development (Ghaffar et al., 2013). The doctor's characteristic data was obtained from comprehensive websites of these institutions and the Pakistan Medical \& Dental Council website. Only registered, permanent faculty members ranked Assistant Professor and above in basic and clinical sciences were selected. Parttime faculty members were not included in the study to avoid duplication. Lecturers, demonstrators, and senior registrars were excluded to maintain uniformity amongst participants. A total of 567 members were identified, out of which the number of registered Professors were 145, 121 Associate Professors, and 301 Assistant Professors in these institutes. Over three weeks, a total number of male and female members along with the number of published articles by each faculty member were identified using "Pakmedinet.com" and "Scholar.google.com".
All analyses were performed in SPSS IBM software version 20.0. A t-test was performed to determine the difference in the number of male and female faculty members, and the difference in the number of publications of male and female members. A one-way ANOVA was used to determine differences between all three groups i.e., Assistant Professors, Associate Professors, and Professors. P-value of less than 0.05 was deliberated as statistically significant.

\section{RESULTS}

Academic productivity of each gender was measured on two parameters: The number of individuals on higher academic ranks and their respective number of publications.

Total male faculty members were 359 in comparison to $208 \mathrm{fe}$ male members (Table I). A significant difference was noted in the male to female ratio of academic hiring $(\mathrm{p}<0.05)$. More male doctors are appointed as Associate Professors and especially Professors in medical institutes.

Table I: Detail of male and female faculty members in three medical institutes

\begin{tabular}{|l|c|c|c|c|c|c|c|c|c|}
\hline \multirow{2}{*}{ Institute } & \multicolumn{4}{|c|}{ Professors } & \multicolumn{3}{c|}{ Associate Professors } & \multicolumn{3}{c|}{ Assistant Professors } \\
\cline { 2 - 11 } & Total & M & F & Total & M & F & Total & M & F \\
\hline Institution 1 & 68 & 47 & 21 & 48 & 31 & 17 & 125 & 73 & 52 \\
\hline Institution 2 & 45 & 36 & 9 & 41 & 27 & 14 & 116 & 56 & 60 \\
\hline Institution 3 & 32 & 29 & 3 & 32 & 19 & 13 & 60 & 41 & 19 \\
\hline Total & 145 & 112 & 33 & 121 & 77 & 44 & 301 & 170 & 131 \\
\hline
\end{tabular}

Table II: Publication gender gap amongst faculty members

\begin{tabular}{|c|c|c|c|c|}
\hline Rank & Gender & $\mathbf{N}$ & $\begin{array}{c}\text { Mean number of } \\
\text { articles }\end{array}$ & Standard Deviation \\
\hline Professor & Female & 265 & 8.030 & 12.512 \\
\hline \multirow{2}{*}{ Associate Professor } & Female & 195 & 4.431 & 6.352 \\
\hline & Male & 694 & 9.012 & 3.451 \\
\hline Assistant Professor & Male & 189 & 1.111 & 3.852 \\
\hline \multirow{2}{*}{ TOTAL } & Female & 523 & 2.514 & 12.023 \\
\hline & Male & 2586 & 7.203 & 36.023 \\
\hline
\end{tabular}

Similarly, a significant gender difference was found between the number of published articles $(\mathrm{p}<0.05)$. The mean number of articles published by Associate Professor and Professor men is 12.68 and those published by Associate Professor and Professor women is 5.97 (Table II). The mean number of articles published by male and female Assistant Professors is 1.11 and 0.4 respectively. These results remained significant across all academic ranks ranging from Assistant Professor to full Professor.

\section{DISCUSSION}

The results of our study indicate a clear gender gap in higher academic medical ranks and research. Gender-based bias and discrimination against female physicians has been a pandemic in both Eastern and Western societies (Burgess et al., 2012). Significantly decreased representation of female doctors at higher positions has been identified in the United States (Mueller et al., 
2017; Carr et al., 2018), New Zealand (McGregor, 2014), England (Nonnemaker, 2000), Japan (Yasukawa \& Nomura, 2014), Sweden (Larsson et al., 2003), India (Bhadra, 2011) etc. As the women climb up the academic ladder, these disparities drastically increase (Buckley et al.,2000; Burgess et al., 2012). None of the studies have been able to define the drivers responsible for this disparity. Some studies suggest lack of mentoring and negotiation skills in women might contribute to less advancement (Mueller et al., 2017), countries like the United States blame less wages of female consultants as a demotivator (Carr et al., 2018).

Although the percentage of female students graduating from medical schools in Pakistan is equal to that of male students (PM\&DC, 2019), this ratio shifts amongst post-graduates with currently registered 15498 females while male specialists are 30741 (2:1) (PM\&DC, 2019). So, the gender gap begins at the level of post-graduation and continues in the higher hierarchy. An article published in 2015 revealed that $38 \%$ of female doctors that graduated in 2005 did not renew their registration. They left their profession or left the country (Hussain, 2015). It is alarming to witness that after 19 years, the situation has not gotten any better.

In our study, we witness a large number of females at the position of Assistant Professor. However, the ratio falls drastically at the Professor level where male Professors are three times more than females. A steady tenure track and an increased number of publications are vital for academic promotions, but our study depicts that female faculty members have significantly lesser publications than male members. The results are in alignment with studies done in other countries (Buckley et al., 2000; Brüggmann \& Groneberg, 2017). In 2017, it was indicated that women are less likely to become Professors in Cardiology (Carne \& Merz, 2017). Similar findings have been observed in department of Surgery (Mueller et al., 2017), radiology (Kapoor et al., 2017), ophthalmology (Gong et al., 2019), anesthesia (Pashkova et al., 2013), internal \& emergency medicine and pediatrics (Jena et al., 2015). Several studies have suggested reasons for such an imbalance; lack of recruitment from medical institutions and unwillingness to retain female faculty members have been observed (Bennett et al., 2019).

In many institutions, female specialists are underpaid than males of same specialization (Jena et al., 2016; Gong et al., 2019). Women more than 40 years of age are more likely to face gender bias than younger women (Yasukawa \& Nomura, 2014). Women receive less research grants than men (Bennett et al., 2019). Women with $\mathrm{PhD}$ degrees have faced rejections more times than those without PhD (Larsson et al., 2003). The biggest reason of female retrogression in South East Asia was the effort to maintain balance in work and family life (Sood \& Chadda, 2010). Females feel overburdened with household responsibilities hence they choose family over career thus delaying their academic advancement opportunities (Sood \& Chadda, 2010). All these reasons may explain the lesser number of female faculty members in medical institutions, but it fails to justify the significantly lower number of publications by full-time female faculty members. Whether female faculty members are discouraged to participate in research, or whether they face more hindrances, or they lack meaningful motivation is still unclear and requires further research.

Our study gives a clear insight into the current gender disparity inside Pakistani Medical Institutes. However, this study has limitations. Only three institutions were chosen to obtain data. The study results would be more reliable with observations from all medical institutes of Pakistan. Furthermore, since the study was aimed at identifying gender gaps, only two parameters were considered. Few reasons for gender discrepancies have been identified in foreign studies. For the future, similar studies need to be conducted in our society to obtain substantial information since our cultural norms are different from the West. In our opinion, identifying reasons for gender bias is important but the need of the hour is to devise ways to address the imbalance and eliminate it. We hope that this study paves the way for future research in gender studies that could lead to concrete reforms in academic diversity.

\section{CONCLUSION}

The results of this study are in alignment with several previous studies that indicate gender disparities between males and females especially as they climb up the academic ladder. Publications are a measure of academic productivity. This study suggests that although female representation as faculty members have increased over the years, their lack of frequent publications might be a factor that hinders women in advancing in academic ranks. Continued studies are required to explore more reasons for this gender inequality and highlight methods to address the stereotypical imbalance.

\section{DECLARATION OF INTEREST}

The author report no declaration of interest.

\section{REFERENCES}

Ali, T. S., Krantz, G., Gul, R., Asad, N., Johansson, E., \& Mogren, I. (2011). Gender roles and their influence on life prospects for women in urban Karachi, Pakistan: a qualitative study. Global Health Action, 4, 7448. https://doi.org/10.3402/gha.v4i0.7448

Bennett, C. L., Raja, A. S., Kapoor, N., Kass, D., Blumenthal, D. M., Gross, N., \& Mills, A. M. (2019). Gender Differences in Faculty Rank Among Academic Emergency Physicians in the United States. Academic Emergency Medicine, 26(3), 281-285. https://doi.org/10.1111/acem.13685

Bhadra, M. (2011). Indian Women in Medicine: An Enquiry Since 1880. Indian Anthropologist, 41(1), 17-43. https://doi. org/10.2307/41921931

Bhatti, M. W. (2019). Around 85000 female doctors not working after getting medical education in Pakistan. Retrieved from https://www.thenews.com.pk/latest/469105-around-85000-female-doctors-not-working-after-getting-medical-education-in-pakistan 
Brüggmann, D., \& Groneberg, D. A. (2017). An index to characterize female career promotion in academic medicine. Journal of Occupational Medicine and Toxicology, 12, 18. https://doi. org/10.1186/s12995-017-0164-7

Buckley, L. M., Sanders, K., Shih, M., Kallar, S., \& Hampton, C. (2000). Obstacles to promotion? Values of women faculty about career success and recognition. Academic Medicine, 75(3), 283288. https://doi.org/10.1097/00001888-200003000-00021

Burgess, D. J., Joseph, A., Van Ryn, M., \& Carnes, M. (2012). Does stereotype threat affect women in academic medicine? Academic Medicine, 87(4), 506-512. https://doi.org/10.1097/ ACM.0b013e318248f718

Carnes, M., \& Noel Bairey Merz, C. (2017, February 7). Women Are Less Likely Than Men to Be Full Professors in Cardiology: Why Does This Happen and How Can We Fix It? Circulation, Vol. 135, pp. 518-520. https://doi.org/10.1161/CIRCULATIONAHA.116.026671

Carr, P. L., Raj, A., Kaplan, S. E., Terrin, N., Breeze, J. L., \& Freund, K. M. (2018). Gender differences in academic medicine: Retention, rank, and leadership comparisons from the national faculty survey. Academic Medicine, Vol. 93, pp. 1694-1699. https://doi.org/10.1097/ACM.2146

Coomaraswamy, R. (2017). To Bellow like a Cow: Women, Ethnicity, and the Discourse of Rights. In Global Minority Rights (pp. 89-107). https://doi.org/10.4324/9781315254203-7

Dhalla, I. A., \& Detsky, A. S. (2011, March 2). Aligning incentives for academic physicians to improve health care quality. JAMA - Journal of the American Medical Association, Vol. 305, pp. 932-933. https://doi.org/10.1001/jama.2011.234

Dhulkhed, V. K., Kurdi, M. S., Dhulkhed, P. V., \& Ramaswamy, A. H. (2016). Faculty promotions in medical institutions in India: Can we improve the criteria? Indian Journal of Anaesthesia, 60(11), 796-800. https://doi.org/10.4103/0019-5049.193657

Ghaffar, A., Zaidi, S., Qureshi, H., \& Hafeez, A. (2013). Medical education and research in Pakistan. The Lancet, Vol. 381, pp. 2234-2236. https://doi.org/10.1016/S0140-6736(13)60146-4

Gong, D., Winn, B. J., Beal, C. J., Blomquist, P. H., Chen, R. W., Culican, S. M., Al-Aswad, L. A. (2019). Gender Differences in Case Volume Among Ophthalmology Residents. JAMA Ophthalmology, 137(9), 1015. https://doi.org/10.1001/jamaophthalmol.2019.2427

Halim, A. M. A. (1999). Reconciling the Opposites: Equal but Subordinate. In Religious Fundamentalisms and the Human Rights of Women (pp. 203-213). https:/doi. org/10.1057/9780230107380_18

Hussain, S. (2015). 38\% lady doctors quit profession in past 5 years. Retrieved from https://www.samaa.tv/uncategorized/2015/08/38-lady-doctors-quit-profession-in-past-5-years
Jena, A. B., Khullar, D., Ho, O., Olenski, A. R., \& Blumenthal, D. M. (2015). Sex differences in academic rank in US medical schools in 2014. JAMA - Journal of the American Medical Association, 314(11), 1149-1158. https://doi.org/10.1001/ jama.2015.10680

Jena, A. B., Olenski, A. R., \& Blumenthal, D. M. (2016). Sex differences in physician salary in US public medical schools. JAMA Internal Medicine, 176(9), 1294-1304. https://doi.org/10.1001/ jamainternmed.2016.3284

Kapoor, N., Blumenthal, D. M., Smith, S. E., Ip, I. K., \& Khorasani, R. (2017). Gender differences in academic rank of radiologists in U.S. medical schools. Radiology, 283(1), 140-147. https://doi.org/10.1148/radiol.2016160950

Larsson, C., Hensing, G., \& Allebeck, P. (2003). Sexual and gender-related harassment in medical education and research training: Results from a Swedish survey. Medical Education, 37(1), 39-50. https://doi.org/10.1046/j.1365-2923.2003.01404.x

McGregor, J. (2014). Academic Careers and the Gender Gap. New Zealand Sociology, 29(1), 197.

Mueller, C., Wright, R., \& Girod, S. (2017). The publication gender gap in US academic surgery. BMC Surgery, 17(1). https://doi. org/10.1186/s12893-017-0211-4

Nonnemaker, L. (2000, February 10). Women physicians in academic medicine: New insights from cohort studies. New England Journal of Medicine, Vol. 342, pp. 399-405. https://doi. org/10.1056/NEJM200002103420606

Nussbaum, M. (1999). Women and Equality: The Capabilities Approach. International Labour Review, 138. Retrieved from https://heinonline.org/HOL/Page?handle=hein.journals/intlr138\&id=235\&div=\&collection

Pashkova, A. A., Svider, P. F., Chang, C. Y., Diaz, L., Eloy, J. A., \& Eloy, J. D. (2013). Gender disparity among US anaesthesiologists: are women underrepresented in academic ranks and scholarly productivity? Acta Anaesthesiologica Scandinavica, 57(8), 1058-1064. https://doi.org/10.1111/aas.12141

PM\&DC. (2019). Statistics Total Number of Doctors / Dental Surgeons (G. P's With Basic Degree Only) Registered Up To 30th September, 2019. Retrieved from http://www.pmdc.org.pk/Statistics/tabid/103/Default.aspx

Rehman, S., \& Roomi, M. A. (2012). Gender and work-life balance: A phenomenological study of women entrepreneurs in Pakistan. Journal of Small Business and Enterprise Development, 19(2), 209-228. https://doi.org/10.1108/14626001211223865

Sood, M., \& Chadda, R. K. (2010). Women in medicine: A perspective. Indian Journal of Gender Studies, 17(2), 277-285. https://doi.org/10.1177/097152151001700204 
Van Der Velden, L. F. J., Hingstman, L., Heiligers, P. J. M., \& Hansen, J. (2008). Increasing number of women in medicine: Past, present and future. Nederlands Tijdschrift Voor Geneeskunde, 152(40), 2165-2171. Retrieved from http://www.ncbi. nlm.nih.gov/pubmed/18953778

Yasukawa, K., \& Nomura, K. (2014). Gender-Based Discrimination among Japanese Physicians 35. Tohoku J. Exp. Med, 232(1), 35-42. https://doi.org/10.1620/tjem.232.35
Zubair, S. (2016). Development narratives, media, and women in Pakistan: shifts and continuities. South Asian Popular Culture, 14(1-2), 19-32. https://doi.org/10.1080/14746689.2016.1241348

\section{AUTHORS CONTRIBUTION}

1. Ayesha Fahim: Review of language references.

2. Fahim Haider Jafari: Review and editing 